\title{
TRAÇOS DE PERSONALIDADE, ATITUDE AO ENDIVIDAMENTO E CONHECIMENTO FINANCEIRO: UM RETRATO DOS SERVIDORES DA UNIVERSIDADE FEDERAL DE SANTA CATARINA
}

\section{Personality Traits, Attitude to Indebtedness, and Financial Knowledge: A Portrait of Employess of the Federal University of Santa Catarina}

\section{Greicy Bainha Pacheco}

Doutoranda em Administração. Universidade Federal de Santa Cataria. Florianópolis, SC. Brasil.e-mail:greicybainha@hotmail.com

\section{Jéssica Pulino Campara}

Doutoranda em Administração. Universidade Federal de Santa Cataria. Florianópolis, SC. Brasil.e-mail:jesvscampara@gmail.com

\section{Newton Carneiro Affonso da Costa Jr.}

Doutorado em Administração de Empresas pela Escola de Administração de Empresas de São Paulo da Fundação Getúlio Vargas. Professor Titular da Universidade Federal de Santa Cataria. Florianópolis, SC. Brasil.e-mail:ncacjr@gmail.com

\section{RESUMO}

As constantes evidências de analfabetismo financeiro, bem como o elevando nível de endividamento da sociedade, faz com que esses temas tenham de ser mais bem explorados para que alternativas a esses problemas possam emergir. Assim, tem-se como objetivo identificar quais aspectos influenciam a atitude ao endividamento e o conhecimento financeiro de servidores da Universidade Federal de Santa Catarina (UFSC) considerando variáveis de perfil e traços de personalidade. Para tanto foi feita uma pesquisa online através de um questionário com os servidores (técnico-administrativos e docentes) da UFSC. Os dados foram analisados através do software SPSS. Os principais resultados, revelados por meio da aplicação de um questionário, demonstraram a predominância dos traços de personalidade "conscienciosidade" e "abertura à experiência", além de indicarem elevado conhecimento financeiro e baixa atitude ao endividamento, o que aponta um perfil menos suscetível a problemas financeiros dentre os servidores. No entanto, ainda há aqueles com maior tendência a apresentarem baixa educação financeira e elevada atitude ao endividamento, sendo os demais resultados direcionados à identificação desses, os quais devem ser priorizados em cursos de capacitação.

Palavras-chave: Traços de personalidade. Atitude ao endividamento. Conhecimento financeiro. Finanças comportamentais. Servidor público.

\section{ABSTRACT}

The constant evidence of financial illiteracy, as well as the raising level of indebtedness of our society, means that these issues need to be better explored, so that alternatives to these problems can emerge. Thus, the objective of this work is to identify which aspects influence the attitude to indebtedness and the financial knowledge of employees of the Federal University of Santa Catarina (UFSC) considering variables of profile and personality traits. The main results, revealed through the application of a questionnaire, showed the predominance of personality traits "conscientiousness" and "openness to experience", in addition to indicating a high financial knowledge and low attitudes to indebtedness, which indicates a profile less susceptible to problems among employees. However, there are still those with a greater tendency to present low financial education and high attitude to indebtedness, and the other results are directed to the identification of these, which should be prioritized in training courses.

Keywords: Personality traits. Attitude to indebtedness. Financial knowledge. 


\section{INTRODUÇÃO}

As constantes transformações econômicas e a própria evolução das finanças fizeram com que as tradicionais teorias financeiras não fossem mais suficientes para explicar determinados comportamentos, principalmente por desconsiderarem a cognição humana (YOSHINAGA et al., 2008). Essa lacuna estimulou o surgimento de uma nova abordagem, capaz de explicar o comportamento nem sempre racional dos agentes econômicos, denominada finanças comportamentais. Essa teoria se alicerçou na concepção de que as decisões são influenciadas por uma série de fatores comportamentais e limites de arbitragem (MILANEZ, 2003) e, que por esse motivo, não podem ser consideradas totalmente racionais.

Além disso, as finanças comportamentais apregoam que cada indivíduo possui suas especificidades e assim não se comportam de maneira padronizada. Essa percepção consolidou uma vertente fértil de estudos nessa área, que se baseiam nos traços de personalidade. Nesse âmbito, exploram-se as dimensões da personalidade, o que tem contribuído e facilitado à compreensão de padrões de comportamento, decisões e resultados no âmbito social e econômico (BORGHANS et al. 2008). Dentre estes padrões de comportamento destaca-se o endividamento que segundo diversos estudos pode ser impactado pela personalidade de cada indivíduo (SILVA; VIEIRA; FAIA, 2012).

A preocupação com o endividamento, principalmente em contexto brasileiro, se dá pelo fato de que o percentual de famílias nesta situação é elevado. Segundo Pesquisa de Endividamento e Inadimplência do Consumidor (Peic) de maio de 2017, realizada pela Confederação Nacional do Comércio de Bens, Serviços e Turismo (CNC, 2017), 57,6\% das famílias brasileiras encontram-se com dívidas e destas $24,2 \%$ estão inadimplentes, sendo que $9,7 \%$ relaram não terem condições nem de quitar seus débitos no futuro. Trazendo para um contexto mais próximo ao da pesquisa, o cenário se agrava, pois, de acordo com a pesquisa realizada pela Fecomércio-SC em dezembro de 2016, Florianópolis é a cidade catarinense com maior percentual $(86,5 \%)$ de famílias endividadas, bem como revela elevado (26,7\%) nível de inadimplência (FECOMÉRCIO-SC, 2016).
Esse panorama preocupa, pois as implicações do endividamento e inadimplência na vida dos indivíduos são diversas, tais como depressão, estresse, doenças do coração, distúrbios do sono dentre outros problemas que limitam a vida (LUCKE et al., 2014). Percebendo essas adversidades buscam-se alternativas que possam amenizar o nível de dívida da população e dentre as ferramentas destaca-se o conhecimento financeiro. Savoia, Saito e Santana (2007) reconhecem que o baixo conhecimento financeiro, implica em maiores dificuldades para compreender os conceitos financeiros básicos e, por consequência, eleva o risco dos indivíduos terem problemas financeiros decorrentes de decisões equivocadas.

Diante do exposto, pode-se conjecturar que os traços de personalidade são fatores determinantes do endividamento e que o conhecimento financeiro atua como uma ferramenta de controle em relação à dívida. Além disso, destaca-se ainda que tanto a atitude ao endividamento quanto o conhecimento financeiro podem ser influenciados por aspectos de perfil. Algumas das possíveis relações são com as variáveis: sexo, idade, estado civil, dependentes, escolaridade, ocupação, moradia e renda, as quais já foram apontadas por estudos anteriores como relacionadas a maiores ou menores níveis de endividamento e de conhecimento financeiro (CLAUDINO; NUNES; SILVA, 2009; FLORES, 2012).

Partindo dessas relações e busca-se responder a seguinte pergunta de pesquisa: "Quais aspectos que influenciam a atitude ao endividamento e o conhecimento financeiro dos servidores da Universidade Federal de Santa Catarina?". Para isso, o presente trabalho tem como objetivo compreender quais os aspectos que influenciam a atitude ao endividamento e o conhecimento financeiro de servidores da Universidade Federal de Santa Catarina (UFSC) considerando aspectos de perfil e traços de personalidade.

Ressalta-se que a importância de investigar servidores públicos está no fato de que na maioria das vezes esses indivíduos possuem um perfil conservador, mas ao mesmo tempo muitas opções financeiras, principalmente vinculadas a facilidades na aquisição de empréstimos, os tornam suscetíveis à dívida. Sendo importante explorar os temas aqui abordados para compreender se efetivamente esses indivíduos estariam mais suscetíveis a problemas 
financeiros. Ademais, estudos anteriores como o de Claudino, Nunes e Silva (2009) e o de Flores, Vieira e Coronel (2013) foram feitos com servidores de outras universidades públicas no Brasil, no entanto a realidade de cada universidade é única, os contextos socioeconômicos das regiões são diferentes, e as variáveis utilizadas também são distintas, sendo assim de grande valia a execução desta pesquisa no contexto da UFSC, principalmente pela importância já destacada dos temas investigados, bem como pelo elevado nível de dívida da população da cidade de Florianópolis. Além disso, é importante destacar que a incorporação dos traços de personalidade como variáveis relacionadas à atitude ao endividamento $\mathrm{e}$ ao conhecimento financeiro é considerada uma inovação, já que pesquisas anteriores tinham como foco apenas o estudo do endividamento e do conhecimento financeiro dos servidores públicos relacionados a variáveis de perfil.

O presente artigo está organizado em: 1) introdução ao tema; 2) referencial teórico; 3 ) metodologia; 4) análise e discussão dos resultados; e por fim 5) considerações finais.

\section{REFERENCIAL TEÓRICO}

\subsection{TRAÇOS DE PERSONALIDADE}

A teoria dos traços de personalidade tem como objetivo principal identificar como as pessoas agem em diferentes contextos ao longo da vida, pois pressupõe que a personalidade é uma hierarquia de traços caracterizados por tendências duradouras que constituem formas de comportamento em diferentes situações (EYSENCK; EYSENCK, 1987). Essa constatação ratifica a complexidade de mensurar os traços de personalidade, que foi amenizada com o surgimento do Modelo dos Cinco Grandes Fatores (Big Five Personality Traits), o qual vem sendo utilizado por descrever as dimensões humanas de forma consistente e replicável (GOSLING; RENTFROW; SWANN JR., 2003). Vale ressaltar que a estrutura do Big Five não determina que existam apenas cinco diferentes traços de personalidade, mas sim, que são dimensões amplamente representativas incluindo características distintas.
Assim, partindo desse modelo, é possível observar o modo como uma pessoa reage quando confrontada, o modo como se relaciona com os outros e a maneira como enxerga o mundo, sendo estas peculiaridades inerentes a cada indivíduo (BORGHANS et al. 2008). Logo, inúmeros podem ser os traços de personalidade existentes, pois como evidenciado cada pessoa comportasse de maneira específica.

Borghans et al. (2008) relata os cinco grandes traços de personalidade como sendo: Neuroticismo (mede a instabilidade emocional da personalidade do indivíduo); Extroversão (mede o nível de energia, a sensação de bem-estar, as habilidades nas relações interpessoais, a necessidade de atenção e o grau de interação social); Abertura à experiência (mede a complexidade do indivíduo e a percepção que a pessoa tem da própria capacidade); Afabilidade (mede a necessidade de a pessoa ser agradável e harmoniosa em suas relações); e Conscienciosidade (mede o grau de concentração do indivíduo, descreve o controle de impulsos e se a pessoa está disposta a cumprir regras, padrões e normas). Esses fatores descrevem as características fundamentais das pessoas, sendo que cada indivíduo vai apresentar uma combinação dos cinco traços da personalidade distinta, podendo haver algum traço que se sobressai, o que não significa que os demais não estejam presentes (BORTOLI; COSTA JR; GOULART, 2015; BORTOLI, 2016).

\subsection{ATITUDE AO ENDIVIDAMENTO}

O Observatório de Endividamento dos Consumidores da Universidade de Coimbra (2002) argumenta que o endividamento é o processo em que os indivíduos comprometem uma parcela significativa de suas rendas e rendimentos para honrá-las no futuro. Vinculado ao endividamento está a inadimplência que ocorre quando uma pessoa contrai uma quantia tão alta de dívida que não tem condições de pagar nos prazos estabelecidos (OLIVATO; SOUZA, 2007), havendo uma circunstância ainda mais extrema, que é o sobreendividamento. Nesses casos o devedor se acha impossibilitado de cumprir com os compromissos financeiros sem pôr em risco a subsistência própria ou da família (ZERRENNER, 2007). 
Além desse conceito, vale salientar outro ponto explorado, principalmente pela área acadêmica que é a atitude ao endividamento. Segundo, Livingstone e Lunt (1992), Lea, Webley e Levine (1993) e Tokunaga (1993) há uma correlação entre atitude ao endividamento e o endividamento. Estes autores afirmam que se as pessoas não puderem evitar dívidas, ajustarão suas atitudes para se tornarem mais tolerantes a elas. No entanto, Davies e Lea (1995) alertam que é preciso saber diferenciar os conceitos, pois embora um indivíduo tenha atitudes favoráveis ao endividamento, não necessariamente ele está endividado. Campara e Vieira (2016) ratificam essa afirmação. Segundo uma pesquisa realizada pelas autoras com beneficiários do Programa Bolsa Família, 63,2\% dos 495 entrevistados possuem dívidas, mas os mesmos tem baixa atitude ao endividamento (média de 2,58 em uma escala de 1 a 5).

Partindo desses esclarecimentos iniciais, questiona-se o que leva as pessoas a elevados níveis de dívida. Buscando essas explicações destaca-se uma pesquisa do Banco Central (2013), que revela como origem das dívidas os seguintes aspectos: despesas sazonais; compras não planejadas ou realizadas por impulso, orçamento deficitário, redução de renda sem redução de despesas, despesas emergenciais, divórcio, ou pouco conhecimento financeiro. Katona (1975), com o mesmo objetivo, defende que existem três razões para uma pessoa gastar mais do que ganha e assim tornar-se inadimplente: 1) baixa renda, impedindo que sejam pagas até mesmo as despesas essenciais; 2) alta renda, aliada a um forte desejo de gastar; ou 3) dificuldade de economizar independente da renda auferida.

Como possíveis consequências do endividamento Katona (1975) destacou tanto questões de ordem psicológicas como a tristeza, ansiedade e nervosismo, quanto questões de ordem social, como problemas nas relações familiares, sociais e até profissionais. De mesmo modo, Lucke et al. (2014) salienta que problemas financeiros podem originar depressão, estresse, alcoolismo e distúrbios do sono, podendo acarretar até em doenças do coração.

Dado aos diversos efeitos negativos que o endividamento causa na vida das pessoas, se busca alternativas que possam amenizar o nível de dívida da população, como proporcionar acesso ao conhecimento financeiro. Nesse sentido, Claudino, Nunes e Silva (2009) e Lusardi e Mitchell (2013) afirmam que um maior conhecimento financeiro por parte do indivíduo reduz a propensão ao endividamento.

\subsection{CONHECIMENTO FINANCEIRO}

Para melhor compreender o conhecimento financeiro, primeiramente é preciso conhecer o significado de Letramento Financeiro. De acordo com a Organização para a Cooperação e Desenvolvimento Econômico (OCDE) (2005), o letramento financeiro, ou alfabetização financeira engloba três dimensões: o Conhecimento Financeiro que trata da compreensão de conceitos e riscos financeiros; a Atitude Financeira que envolve motivação e confiança para aplicar o conhecimento financeiro; e por fim, o Comportamento Financeiro que deve levar a tomadas de decisões eficazes em diferentes contextos financeiros.

Assim, entende-se que o Conhecimento Financeiro ou também chamada Educação Financeira é apenas uma das dimensões do letramento financeiro, que envolve um processo de aprendizagem para aperfeiçoar e aprofundar os conhecimentos, fazendo com que os indivíduos sejam capazes de gerenciar de maneira eficiente seus recursos financeiros a fim de tomarem decisões conscientes em relação aos recursos disponíveis e, consequentemente, aperfeiçoar as práticas orçamentárias visando o momento atual sem deixar de planejar o futuro (VERDINELLI; LIZOTE; OLIVARES, 2014). De maneira mais detalhada, a OCDE define conhecimento financeiro como:

\footnotetext{
“[...] processo mediante o qual os indivíduos e as sociedades melhoram a sua compreensão em relação aos conceitos e produtos financeiros, de maneira que, com informação, formação e orientação, possam desenvolver os valores e as competências necessários para se tornarem mais conscientes das oportunidades e riscos nelas envolvidos e, então, poderem fazer escolhas bem informadas, saber onde procurar ajuda e adotar outras ações que melhorem o seu bem-estar (OCDE, 2005)”.
}

A ausência dessas características leva ao analfabetismo financeiro que é uma barreira para a inclusão financeira, bem como para melhores tomadas de decisão, o que infelizmente é identificado em boa 
Greicy Bainha Pacheco • Jéssica Pulino Campara • Newton Carneiro Affonso da Costa Jr.

parte do mundo. Quem apontou isso foi a $S \hookleftarrow P$ Global Finance Literacy Survey ${ }^{1}$, uma pesquisa global sobre conhecimento financeiro. Tal estudo, realizado com mais de 150 mil adultos em mais de 140 países, investigou conhecimentos a respeito de aritmética; diversificação do risco; inflação e juros compostos e evidenciou que apenas $33 \%$ dos adultos no mundo têm conhecimento financeiro. Entre os países com maior nível de conhecimento financeiro estão Di- namarca, Noruega e Suécia, enquanto que o Brasil ocupa a $67^{\mathrm{a}}$ posição no ranking, abaixo de alguns dos países mais pobres do globo, como Madagascar, Togo e Zimbabué (KLAPPER; LUSARDI; OUDHEUSDEN, 2015). Resultados mais detalhados apontaram que aritmética e inflação foram considerados os conceitos mais entendidos pela população, já diversificação do risco foi o conceito menos compreendido (KLAPPER; LUSARDI; OUDHEUSDEN, 2015).

Quadro 1 Relação esperada das variáveis com os fatores

\begin{tabular}{|c|c|c|}
\hline Variável & $\begin{array}{l}\text { Relação Esperada entre o } \\
\text { endividamento e as variáveis de perfil }\end{array}$ & Autores \\
\hline \multirow{2}{*}{ Sexo } & Homens = maior endividamento. & $\begin{array}{l}\text { Baek e Hong (2004); Flores (2012); Huang e } \\
\text { Kisgen (2013) }\end{array}$ \\
\hline & Mulheres = maior endividamento. & Berg et al. (2010) \\
\hline Idade & Maior idade = menor endividamento. & Ponchio (2006); Wang et al. (2011); Flores (2012) \\
\hline Estado Civil & Solteiros = maior endividamento. & $\begin{array}{l}\text { Nogueira (2009); Disney e Gathergood (2011); } \\
\text { Flores (2012) }\end{array}$ \\
\hline \multirow{2}{*}{ Dependentes } & Ter dependentes = maior endividamento & Keese (2010); Wang et al. (2011) \\
\hline & Ter dependentes $=$ menor endividamento & Flores (2012) \\
\hline Escolaridade & Mais escolaridade $=$ menor endividamento & $\begin{array}{l}\text { Ponchio (2006); Claudino, Nunes e Silva (2009); } \\
\text { Disney e Gathergood (2011); Keese (2012); Flores } \\
\text { (2012); Flores, Vieira e Coronel (2013) }\end{array}$ \\
\hline \multirow{2}{*}{ Ocupação } & Desempregados = maior endividamento. & Disney e Gathergood (2011) \\
\hline & Servidor público = menor endividamento & Campara, Flores e Vieira (2016) \\
\hline Moradia & Morar sozinho = maior endividamento. & $\begin{array}{l}\text { Keese (2010); Disney e Gathergood (2011); Flores } \\
\text { (2012) }\end{array}$ \\
\hline Renda & Menor renda = maior endividamento. & $\begin{array}{l}\text { Katona (1975); Stone e Maury (2006); Claudino, } \\
\text { Nunes e Silva (2009); Flores (2012) }\end{array}$ \\
\hline Variável & $\begin{array}{l}\text { Relação Esperada entre o conhecimento financeiro e as variáveis } \\
\text { de perfil }\end{array}$ & Autores \\
\hline Sexo & Homens = maior conhecimento financeiro. & Klapper, Lusardi e Oudheusden (2015) \\
\hline Idade & Maior idade = menor conhecimento financeiro. & Claudino, Nunes e Silva (2009). \\
\hline Estado Civil & Solteiros = menor conhecimento financeiro. & Potrich et al. (2014) \\
\hline Escolaridade & Maior escolaridade = maior conhecimento financeiro & Claudino, Nunes e Silva (2009). \\
\hline Tempo de Serviço & Mais tempo de serviço = maior conhecimento financeiro & Potrich et al. (2014) \\
\hline Renda & Maior renda = maior conhecimento financeiro & $\begin{array}{l}\text { Claudino, Nunes e Silva (2009); Potrich et al. } \\
\text { (2014); Atkinson e Messy (2012) }\end{array}$ \\
\hline Crédito Consignado & Uso de crédito consignado = menor conhecimento financeiro & Pinheiro (2008) \\
\hline
\end{tabular}

Fonte: Elaborado pelos autores (2017).

\footnotetext{
${ }_{1}$ Ressalta-se que a pesquisa possui Finance Literacy (letramento financeiro) em seu título, mas seu foco de análise é o conhecimento financeiro.
} 


\subsection{RELAÇÃO DAS VARIÁVEIS DE PERFIL COM OS FATORES INVESTIGADOS}

Com base em pesquisas anteriores, é possível observar algumas relações a serem esperadas entre as variáveis de perfil e os fatores investigados. Neste sentido, entende-se que dependendo do perfil do indivíduo é possível esperar uma relação de maior ou menor atitude favorável ao endividamento, bem como em relação ao conhecimento financeiro. Assim, para ilustrar de forma mais esclarecedora essas relações, apresenta-se o Quadro 1, no qual são elencadas as relações entre as variáveis de perfil e os dois fatores explorados (endividamento e conhecimento financeiro).

Essas possíveis relações demonstram a importância do estudo para compreender o perfil do servidor quanto ao conhecimento financeiro e atitude ao endividamento, principalmente pelo fato de que ainda não há um consenso na literatura de qual seriam os perfis de maior risco.

\section{METODOLOGIA}

Os sujeitos da pesquisa foram os servidores (técnico-administrativos e docentes), dos cinco campi da Universidade Federal de Santa Catarina (UFSC), que segundo informação fornecida pela Pró-Reitoria de Gestão e Desenvolvimento de Pessoas totalizam 5.500 servidores, sendo essa a população do estudo. Ressalta-se que a composição da amostra se deu por conveniência, sendo assim não probabilística ${ }^{2}$.

Para a coleta dos dados foi utilizado um questionário composto por 35 questões, desenvolvido com 4 blocos de perguntas: $1^{\circ}$ ) perfil dos respondentes; $\left.2^{\circ}\right)$ Big Five Inventory - 10: criado por Rammstedt $\mathrm{e}$ John (2007) permitiu identificar os traços de personalidade dos servidores (ressalta-se que essa escala apresenta correlação de $82 \%$ com teste mais longos do Big Five); $3^{\circ}$ ) conhecimento financeiro: desenvolvido inicialmente por Klapper, Lusardi e Oudheusden (2015) possibilitou identificar conceitos básicos de finanças e $4^{\circ}$ ) atitude ao endividamento: elaborado originalmente por Lea, Webley e Levine (1993) e validada em contexto brasileiro por Moura (2005) explora a atitude dos respondentes com relação ao endividamento. No início do questionário foi informado que a participação era opcional e que os dados seriam tratados de forma anônima, foram fornecidas também instruções para o adequado preenchimento de cada etapa.

O questionário foi enviado para o e-mail de 5.266 servidores por meio de um formulário desenvolvido em uma ferramenta de pesquisa online (Survey Monkey). Ele ficou disponível para respostas durante 10 dias. Ao final foram coletadas 524 respostas (taxa retorno de $9,27 \%$ ), no entanto, algumas estavam incompletas e por isso foram descartadas, restando um total de 488 respostas completas entre docentes e técnico-administrativos.

Para análise dos dados utilizou-se o software SPSS, no qual foi estimada a estatística descritiva, testes de diferença de média e regressão múltipla. Para análise descritiva do perfil dos servidores e dos fatores investigados (traços de personalidade, conhecimento financeiro e atitude ao endividamento) utilizou-se as seguintes medidas de posição: frequência, média, mediana e desvio padrão. Os testes de diferença de média utilizados foram os testes t e Anova, os quais permitiram identificar se há relação entre o perfil dos servidores e a atitude ao endividamento e conhecimento financeiro. Por fim, a regressão linear múltipla foi adotada com o objetivo de verificar a influência dos traços de personalidade e variáveis de perfil nos dois fatores explorados.

\section{ANÁLISE E DISCUSÃO DOS RESULTADOS}

Inicialmente, buscou-se identificar o perfil dos respondentes da pesquisa por meio da estatística descritiva das variáveis: sexo, idade, estado civil, dependentes, nível de escolaridade, cargo, tempo de serviço, moradia, renda, gastos e crédito consignado. Dessa forma observou-se que o perfil predominante nos servidores da UFSC que responderam a pesquisa

2 Para fins de comparação, caso a amostra tomada fosse aleatória simples (onde cada elemento da população tivesse a mesma probabilidade de pertencer à amostra), um número de 359 servidores entrevistados garantiria $95 \%$ de confiança e $5 \%$ de erro amostral, mas como esse tipo de amostra dificulta imensamente a realização da pesquisa optou-se com uma amostra não probabilística. 
é: $54,10 \%$ pertencem ao sexo feminino; $32,52 \%$ apresentam faixa de idade entre 31 e 40 anos; 60,86\% são casados(as); $55,53 \%$ possuem dependentes; $82,79 \%$ possuem algum nível de pós-graduação; $56,35 \%$ são técnico-administrativos; $66,19 \%$ trabalham na UFSC entre 0 e 8 anos; $51,02 \%$ possuem casa própria; $30,94 \%$ encontram-se na faixa de 3 a 6 salários mínimos; 59,22\% gastam menos do que ganham; e
$64,34 \%$ nunca fizeram uso de nenhum tipo de crédito consignado.

É possível comparar, no Quadro 2, os dados obtidos neste estudo com os servidores da UFSC, com o estudo de Flores, Vieira e Coronel (2013) realizado com servidores da UFSM sobre a propensão ao endividamento.

Quadro 2 Comparação perfil dos servidores da UFSC e da UFS

\begin{tabular}{|c|c|c|}
\hline Variáveis & UFSC & UFSM \\
\hline Sexo & Feminino $(54,10 \%)$ & Feminino $(51,60 \%)$ \\
\hline Idade & Média de 42 anos & Média de 44 anos \\
\hline Estado civil & Casado $(60,86 \%)$ & Casado $(64,80)$ \\
\hline Dependentes & $\operatorname{sim}(55,53 \%)$ & $\operatorname{sim}(60,50 \%)$ \\
\hline Escolaridade & Nível superior $(95,29 \%)$ & Nível superior (83,30\%) \\
\hline Cargo & Técnicos administrativos em educação (56,35\%) & Técnicos administrativos em Educação (70,1\%) \\
\hline Tempo de Serviço & Média de 10 anos & Média de 15 anos \\
\hline Moradia & Casa própria $(51,02 \%)$ & Casa própria $(64,06 \%)$ \\
\hline Faixa de Renda & Entre $\mathrm{R} \$ 2.640,01$ a $\mathrm{R} \$ 5.280,00(30,94 \%)$ & Entre $\mathrm{R} \$ 2.665,01$ a $\mathrm{R} \$ 4.300,00$ (25,80\%) \\
\hline Gastos & Gasta menos do que ganha $(59,22 \%)$ & Gasta menos do que ganha $(58,80 \%)$ \\
\hline Período de realização & Novembro de 2016 & Novembro de 2011 \\
\hline No de respondentes & 488 & 246 \\
\hline
\end{tabular}

Fonte: Elaborado pelos autores.

Como se pode observar, no geral, os perfis dos servidores de ambas as Universidades Federais são semelhantes. Mesmo os estudos tendo sido realizados em períodos diferentes e com diferentes quantidades de servidores, é possível constatar um padrão nas respostas. Isso acontece, muito provavelmente, por refletir uma realidade de Universidades Federais, revelando homogeneidade desses ambientes, ainda que em diferentes Estados.

Após conhecer o perfil dos servidores, foram verificados os traços de personalidade dos respondentes, utilizando a escala do Big Five proposta por Rammstedt e John (2007). Na Tabela 1, foram apresentadas as frequências de cada uma das respostas. 
Tabela 1 Frequências das respostas no teste de traços de personalidade.

\begin{tabular}{c|l|c|c|c|c|c}
\hline \multirow{2}{*}{ Dimensão*** Questões } & \multicolumn{1}{|c|}{$\begin{array}{c}\text { Discordo } \\
\text { totalmente }\end{array}$} & $\begin{array}{c}\text { Discordo } \\
\text { em parte }\end{array}$ & $\begin{array}{c}\text { Não con- } \\
\text { cordo, nem } \\
\text { discordo. }\end{array}$ & $\begin{array}{c}\text { Concordo } \\
\text { em parte }\end{array}$ & $\begin{array}{c}\text { Concordo } \\
\text { totalmente }\end{array}$ \\
\hline \multirow{2}{*}{1} & É reservado. & 110 & 233 & 50 & 59 & 36 \\
\cline { 2 - 9 } & É sociável, extrovertido. & 14 & 78 & 67 & 217 & 112 \\
\hline \multirow{2}{*}{2} & Geralmente confia nas pessoas. & 23 & 94 & 68 & 230 & 73 \\
\cline { 2 - 9 } & Tende a ser crítico com os outros.* & 85 & 252 & 78 & 63 & 10 \\
\hline \multirow{3}{*}{3} & Tende a ser preguiçoso.* & 16 & 72 & 70 & 126 & 204 \\
\cline { 2 - 9 } & Insiste até concluir a tarefa ou o trabalho. & 14 & 28 & 22 & 144 & 280 \\
\hline \multirow{2}{*}{4} & É relaxado, controla bem o estresse.* & 34 & 151 & 66 & 152 & 85 \\
\cline { 2 - 9 } & Fica nervoso facilmente. & 74 & 141 & 90 & 137 & 46 \\
\hline \multirow{2}{*}{5} & Tem poucos interesses artísticos.* & 39 & 104 & 62 & 132 & 151 \\
\cline { 2 - 8 } & Tem uma imaginação fértil. & 18 & 46 & 84 & 181 & 159 \\
\hline
\end{tabular}

Fonte: Dados da pesquisa (2016).

* Variável já invertida.

** (1) Extroversão;(2) Afabilidade; (3) Conscientização; (4) Neuroticismo; e (5) Abertura à experiência.

A partir da Tabela 1 foi possível observar que a maioria dos servidores não são reservados, tendem a ser sociáveis e extrovertidos, geralmente confiam nas pessoas, não são críticos com os outros, possuem uma predisposição a ser preguiçosos e insistem até concluir uma tarefa ou trabalho. Na Tabela 2 são apresentadas as frequências e porcentagens de cada traço de personalidade dos servidores da UFSC que responderam a pesquisa, considerando a orientação de Bortoli (2016):

Tabela 2 Resultado do teste de traços de personalidade

\begin{tabular}{|c|c|c|c|c|c|c|}
\hline \multirow{2}{*}{$\begin{array}{c}\text { Traço de } \\
\text { Personalidade }\end{array}$} & \multicolumn{2}{|c|}{ Baixo (1) } & \multicolumn{2}{|c|}{ Médio (5) } & \multicolumn{2}{|c|}{ Alto (10) } \\
\hline & Frequência & $\%$ & Frequência & $\%$ & Frequência & $\%$ \\
\hline Extroversão & 102 & $20,90 \%$ & 78 & $15,98 \%$ & 308 & $63,11 \%$ \\
\hline Afabilidade & 95 & $19,47 \%$ & 80 & $16,39 \%$ & 313 & $64,14 \%$ \\
\hline Conscienciosidade & 10 & $2,05 \%$ & 23 & $4,71 \%$ & 455 & $93,24 \%$ \\
\hline Neuroticismo & 125 & $25,61 \%$ & 56 & $11,48 \%$ & 307 & $62,91 \%$ \\
\hline Abertura à experiência & 23 & $4,71 \%$ & 45 & $9,22 \%$ & 420 & $86,07 \%$ \\
\hline
\end{tabular}

Fonte: Dados da pesquisa (2016). 
Os resultados demonstram predominantemente que os participantes possuem "Alta" característica de personalidade em todas as dimensões, mas destacam-se a conscienciosidade e a abertura a experiência. No caso de conscienciosidade, 93,24\% dos participantes apresentam "Alta" característica nesta dimensão, indicando que são confiáveis, organizados, cautelosos e disciplinados. Dos participantes, $86,07 \%$ também indicam possuir "Alta" abertura a experiência, o que demonstra que eles são pessoas com amplos interesses, liberais, curiosas e gostam de novidades. Esses resultados são bastante semelhantes com os encontrados por Bortoli (2016) em pesquisa realizada com alunos de graduação da UFSC.
Adentrando no fator atitude ao endividamento, relata-se que o mesmo apresentou um alfa de Cronbach ${ }^{3}$ igual a 0,6. Ressalta-se que essa escala de atitude ao endividamento é subdividida em três dimensões: o impacto sobre a moral na sociedade (engloba o patrimônio, valores e crenças encontrados em sociedade, que podem influenciar a atitude do indivíduo em relação ao endividamento); preferência no tempo (envolve a escolha dos indivíduos entre valor e tempo de um consumo) e grau de autocontrole (define a capacidade para gerir os próprios recursos financeiros, tomar decisões e manter o controle do orçamento). Dessa forma, com base nos dados da Tabela 4, buscou-se compreender a atitude ao endividamento dos servidores da UFSC.

Tabela 3 Resultado do teste de atitude ao endividamento.

\begin{tabular}{|c|c|c|c|c|c|c|c|c|}
\hline 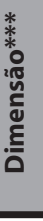 & Questões & \multicolumn{2}{|c|}{ Média** } & \multirow{2}{*}{ 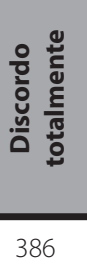 } & \multirow{2}{*}{ 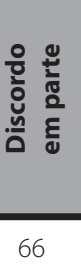 } & \multirow{2}{*}{ 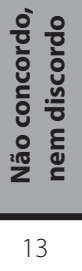 } & \multirow{2}{*}{ 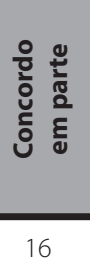 } & \multirow{2}{*}{ 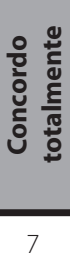 } \\
\hline \multirow{3}{*}{1} & Não é certo gastar mais do que ganho.* & 1,344 & \multirow{3}{*}{2,151} & & & & & \\
\hline & $\begin{array}{l}\text { Acho normal as pessoas ficarem endividadas para } \\
\text { pagar suas coisas. }\end{array}$ & 1,855 & & 256 & 126 & 34 & 65 & 7 \\
\hline & $\begin{array}{l}\text { As pessoas ficariam desapontadas comigo se } \\
\text { soubessem que eu tenho dívida.* }\end{array}$ & 3,254 & & 45 & 88 & 166 & 76 & 113 \\
\hline \multirow{3}{*}{2} & $\begin{array}{l}\text { É melhor primeiro juntar dinheiro e só depois } \\
\text { gastar.* }\end{array}$ & 1,984 & \multirow{3}{*}{2,113} & 178 & 206 & 47 & 48 & 9 \\
\hline & $\begin{array}{l}\text { Prefiro comprar parcelado a esperar ter dinheiro } \\
\text { para comprar a vista. }\end{array}$ & 2,625 & & 128 & 128 & 61 & 141 & 30 \\
\hline & $\begin{array}{l}\text { Prefiro pagar parcelado mesmo que no total seja } \\
\text { mais caro. }\end{array}$ & 1,732 & & 294 & 109 & 23 & 46 & 16 \\
\hline \multirow{3}{*}{3} & $\begin{array}{l}\text { Eu sei exatamente quanto devo em lojas, cartão } \\
\text { de crédito ou banco.* }\end{array}$ & 1,605 & \multirow{3}{*}{1,967} & 345 & 73 & 16 & 26 & 28 \\
\hline & $\begin{array}{l}\text { É importante saber controlar os gastos da minha } \\
\text { casa. }^{*}\end{array}$ & 1,076 & & 459 & 24 & 3 & 1 & 1 \\
\hline & $\begin{array}{l}\text { Não tem problema ter dívida se eu sei que posso } \\
\text { pagar. }\end{array}$ & 3,219 & & 75 & 99 & 49 & 174 & 91 \\
\hline
\end{tabular}

Fonte: Dados da pesquisa (2016).

* Variável já invertida.

* Quanto maior a média das respostas maior a atitude ao endividamento.

*** (1) Impacto sobre a moral na sociedade; (2) Preferência no tempo; (3) Grau de autocontrole.

3 Mede a confiabilidade de uma escala, que segundo Hair et al. (2010) deve ser de no mínimo de 0,6 para estudos exploratórios. Para maiores informações sugere-se a leitura de Hair et al. (2010). 
De maneira geral, identifica-se que no fator atitude ao endividamento, a média das variáveis fixa-se em torno de 2, mostrando que a amostra tem pouca atitude favorável ao endividamento, corroborando com o estudo de Flores, Vieira e Coronel (2013). Tal achado é positivo, na medida em que demonstra que os servidores não se deixam influenciar pelos valores impostos pela sociedade, sabem lidar com a relação de tempo e consumo e ainda apresentam certo grau de autocontrole (MOURA, 2005).

Considerando as médias de cada dimensão é possível observar que: os servidores possuem uma percepção desfavorável frente à dívida (média 2,151 "Impacto sobre a moral na sociedade"), lidam bem com a relação entre valor e tempo (média 2,113 "Preferência no Tempo"), demonstrando paciência para seleção da alternativa mais vantajosa, e possuem habilidade em gerir o próprio dinheiro, tomar decisões financeiras, controlar o orçamento e compreender aspectos financeiros básicos (média 1,967 "Grau de Autocontrole").

Por fim, explorando o conhecimento financeiro, observou-se que $67,62 \%$ dos servidores apresentam conhecimentos básicos em finanças, sendo que esse resultado foi verificado mediante o acerto de pelo menos três dos quatro conceitos investigados. A Tabela 3 ilustra tais achados detalhadamente para cada uma das variáveis.

Tabela 4 Resultado do teste de conhecimento financeiro

\begin{tabular}{|c|c|c|c|}
\hline Conceito & Variáveis & Opções de resposta & Percentual \\
\hline \multirow{3}{*}{ 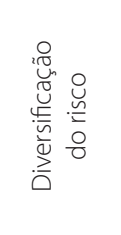 } & \multirow{3}{*}{$\begin{array}{l}\text { Suponha que você tenha algum dinheiro. Você considera mais seguro } \\
\text { coloca-lo em um negócio ou investimento, ou coloca-lo em várias } \\
\text { empresas ou investimentos? }\end{array}$} & $\begin{array}{l}\text { Um negócio ou investi- } \\
\text { mento }\end{array}$ & $41,39 \%$ \\
\hline & & $\begin{array}{l}\text { Várias empresas ou } \\
\text { investimentos* }\end{array}$ & $38,11 \%$ \\
\hline & & Não sei & $20,49 \%$ \\
\hline \multirow{4}{*}{ 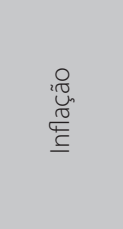 } & \multirow{4}{*}{$\begin{array}{l}\text { Suponha que ao longo dos próximos } 10 \text { anos os preços das coisas } \\
\text { que você compra dupliquem. Se o seu rendimento também duplicar, } \\
\text { você será capaz de comprar menos do que você pode comprar hoje, } \\
\text { o mesmo que você pode comprar hoje, ou mais do que você pode } \\
\text { comprar hoje? }\end{array}$} & Menos & $23,36 \%$ \\
\hline & & O mesmo* & $64,14 \%$ \\
\hline & & Mais & $8,40 \%$ \\
\hline & & Não sei & $4,10 \%$ \\
\hline \multirow{3}{*}{ 苍 } & \multirow{3}{*}{$\begin{array}{l}\text { Suponha que você precise pegar emprestados } R \$ 100,00 \text {. Quando for } \\
\text { pagar essa dívida, qual o valor mais barato: } R \$ 105,00 \text { ou } R \$ 100,00 \text {, mais } \\
\text { três } 3 \% \text { ? }\end{array}$} & $R \$ 105,00$ & $6,56 \%$ \\
\hline & & $\mathrm{R} \$ 100,00$ mais $3 \%^{*}$ & $86,27 \%$ \\
\hline & & Não sei & $7,17 \%$ \\
\hline \multirow{7}{*}{ 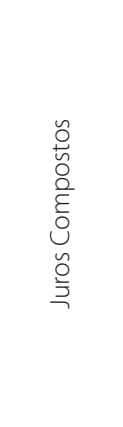 } & \multirow{3}{*}{$\begin{array}{l}\text { Suponha que você coloque seu dinheiro no banco por dois anos e } \\
\text { que o banco deposite um juro de } 15 \% \text { ao ano na sua conta. Será que o } \\
\text { banco irá adicionar mais dinheiro para a sua conta no segundo ano do } \\
\text { que adicionou no primeiro ano, ou vai adicionar a mesma quantidade } \\
\text { de dinheiro ambos os anos? }\end{array}$} & Mais* & $86,89 \%$ \\
\hline & & O mesmo & $3,48 \%$ \\
\hline & & Não sei & $9,63 \%$ \\
\hline & \multirow{4}{*}{$\begin{array}{l}\text { Suponha que você tenha } R \$ 100,00 \text { em uma conta poupança e o banco } \\
\text { deposita um juro de } 10 \% \text { ao ano na sua conta. Quanto dinheiro você } \\
\text { terá na conta depois de cinco anos se você não remover qualquer } \\
\text { dinheiro da conta? }\end{array}$} & Mais de $\mathrm{R} \$ 150,00^{*}$ & $82,99 \%$ \\
\hline & & Exatamente $\mathrm{R} \$ 150,00$ & $5,53 \%$ \\
\hline & & Menos de $\mathrm{R} \$ 150,00$ & $5,33 \%$ \\
\hline & & Não sei & $6,15 \%$ \\
\hline
\end{tabular}

Fonte: Dados da pesquisa (2016).

* Respostas corretas. 
Na primeira questão, referente à diversificação do risco, apenas $38,11 \%$ responderam corretamente, demonstrando que boa parte dos servidores não compreende que a diversificação dos investimentos é fundamental para a diluição dos riscos. Na segunda questão, sobre inflação, $64,14 \%$ responderam corretamente comprovando uma maior facilidade com o tema, provavelmente por este ser um assunto recorrente na mídia e que todas as pessoas de alguma maneira já ouviram falar. Na terceira questão, relacionada à aritmética, $86,27 \%$ responderam corretamente, o que é um bom indicativo, considerando que, cálculos básicos como estes são de extrema importância nas atividades do dia-a-dia. Por fim, nas duas últimas questões, correspondentes aos juros, 86,89\% e 82,99\% respectivamente acertaram as respostas, demonstrando facilidade em compreender a desvalorização do dinheiro ao longo do tempo, bem como a habilidade em resolver cálculos que incorporem taxas de juros. Esse resultado positivo pode ser justificado pelo fato dessas pessoas atuarem justamente em uma institui- ção de ensino superior e a possibilidade de acesso à educação ser maior do que em outras instituições.

Comparando esses resultados com os auferidos por Flores, Vieira e Coronel (2013) percebe-se que os servidores da UFSC $(67,62 \%)$ possuem maior conhecimento financeiro do que os da UFSM (46\%). No entanto, mesmo que os servidores da UFSC tenham maior educação financeira do que os de outras instituições e que, de mesmo modo, revelem maior conhecimento que a média nacional (KLAPPER; LUSARDI; OUDHEUSDEN, 2015), é preciso ressaltar que ainda assim é necessário investir na capacitação dos $32,38 \%$ que demonstraram não ter conhecimento financeiro, para que assim possam ter maior segurança na tomada de decisão e não ficarem expostos de maneira ingênua aos diversos produtos financeiros oferecidos para servidores públicos.

Posterior a essas primeiras evidenciações busca-se identificar a relação das variáveis de perfil com os fatores investigados. Para isso, apresentam-se os resultados do teste t e anova na Tabela 5 .

Tabela 5 Testes de diferenças de médias dos fatores atitude ao endividamento e conhecimento financeiro com relação às variáveis de perfil que se mostraram significativas.

\begin{tabular}{l|c|c|c|c}
\hline \multirow{2}{*}{ Variáveis } & \multicolumn{2}{|c|}{ Atitude ao endividamento } & \multicolumn{2}{c}{ Conhecimento financeiro } \\
\cline { 2 - 5 } & Valor & Sig. & 11,388 & Sig. \\
\hline Sexo & 1,582 & 0,624 & 4,481 & 0,000 \\
\hline Idade & 0,731 & 0,534 & 3,636 & 0,004 \\
\hline Tempo de serviço & 0,852 & 0,466 & 1,016 & 0,013 \\
\hline Moradia & 2,847 & 0,024 & 5,234 & 0,398 \\
\hline Gastos & 33,803 & 0,000 & 6,210 & 0,006 \\
\hline Crédito Consignado & 22,317 & 0,000 & 0,002 \\
\hline
\end{tabular}

Fonte: Dados da pesquisa (2016).

* Foram suprimidas da tabela as variáveis que não se mostraram significativas para o modelo: Estado Civil, Dependente, Nível de Escolaridade, Cargo e Renda

Analisando as relações significativas para o fator atitude ao endividamento, percebe-se que a moradia, gastos e crédito consignado mostraram-se significativas, ou seja, há diferença de média entre esses grupos e a atitude ao endividamento. Neste sentido, pontualmente em relação à moradia identifica-se que servidores residentes em moradias financiadas (média 2,17 ) possuem maior atitude ao endividamento do que aqueles que moram com os pais (média 1,80). No estudo de Flores, Vieira e Coronel (2013) com os servidores da UFSM, a moradia não possui relação com a atitude ao endividamento.

Com relação aos gastos observou-se que servidores que gastam mais do que ganham (média 2,40) possuem maior atitude ao endividamento, confirmando os resultados encontrados por Flores (2012). 
Neste mesmo sentido, servidores que fazem (média 2,33 ) ou já fizeram uso do crédito consignado (média $2,13)$ são os com maior atitude ao endividamento. Aliado a isso, destaca-se que Lira (2014) ao realizar um estudo com servidores da Universidade Federal de Pernambuco constatou que um número excessivo de servidores faz contratos de empréstimos, sendo que muitas vezes firmam mais de um consignado com diferentes bancos, sendo esta uma das maiores vulnerabilidades financeiras desses indivíduos.

$\mathrm{Na}$ sequência, investigado as variáveis que se mostram relevantes para a consolidação do conhecimento financeiro aponta-se o sexo, idade, tempo de serviço, gastos e crédito consignado. Quanto ao sexo, constatou-se que os homens possuem maior média de conhecimento financeiro (média 3,79) do que as mulheres (média 3,40), apoiando assim os resultados encontrados por Klapper, Lusardi e Oudheusden (2015). O que confirma também as pesquisas de Lusardi e Wallace (2013) e Mottola (2013) que afirmam que as mulheres apresentam mais dificuldades com assuntos financeiros.

Observando a variável “idade” percebe-se que os servidores jovens (até 33 anos) pertencem ao grupo com mais conhecimento financeiro (média 3,83) contrastando com servidores que possuem idade entre 41 e 51 anos, os quais apontam pior desempenho (média 3,37). Resultado semelhante foi obtido por Claudino, Nunes e Silva (2009) em estudo realizado com os servidores da Universidade Federal de Viçosa, no qual foi verificado que a idade é inversamente proporcional ao conhecimento financeiro, pois servido- res mais jovens têm maior conhecimento financeiro do que servidores mais velhos. Quanto ao tempo de serviço, os servidores que trabalham entre 6 e 18 anos possuem maior nível de conhecimento financeiro (média 3,76). Potrich et al. (2014) apontaram que indivíduos com mais tempo de serviço passam por mais experiências financeiras e assim adquirem maiores conhecimentos financeiros que facilitam a tomada de decisão financeira.

Ao relacionar os gastos dos servidores com o fator conhecimento financeiro, é possível observar que aqueles que gastam menos do que ganham possuem maior média $(3,72)$ de conhecimento financeiro, ratificando os estudos que indicam que a educação financeira atua como uma medida de controle para a utilização consciente do dinheiro (DELAVANDE; ROHWEDDER; WILLIS, 2008). Partindo dessa mesma argumentação, constata-se ainda o não uso do crédito consignado (média 3,69) está relacionado ao maior conhecimento financeiro. Pinheiro (2008) alerta que a falta de conhecimento financeiro é um grande problema para aqueles que adquirem empréstimos consignados.

Com base nos resultados obtidos, e corroborando com os estudos de Flores (2012), Moura (2005), Lira (2014), Klapper, Lusardi e Oudheusden (2015), Claudino, Nunes e Silva (2009), Potrich et al. (2014) e Pinheiro (2008) foi possível construir uma síntese das variáveis significativas para esta pesquisa no Quadro 3 evidenciando o perfil de risco dos servidores.

Quadro 3 Síntese teste te ANOVA das variáveis que foram significativas.

\begin{tabular}{l|l|l}
\hline \multicolumn{1}{c|}{ Fator } & \multicolumn{1}{c|}{ Variáveis Significativas } & \multicolumn{1}{c}{ Relação encontrada } \\
\hline \multirow{2}{*}{$\begin{array}{l}\text { Servidores com elevada } \\
\text { Atitude ao Endividamento }\end{array}$} & Moradia & Moradia financiada \\
\cline { 2 - 3 } & Gastos & Gasta mais do que ganha \\
\cline { 2 - 3 } & Crédito consignado & Quem faz ou já fez uso do crédito consignado \\
\hline \multirow{3}{*}{$\begin{array}{l}\text { Servidores com baixo } \\
\text { Conhecimento Financeiro }\end{array}$} & Sexo & Mulheres \\
\cline { 2 - 3 } & Idade & Maior idade \\
\cline { 2 - 3 } & Tempo de serviço & Genor tempo de serviço \\
\cline { 2 - 3 } & Gastos & Quem faz ou já fez uso do crédito consignado \\
\cline { 2 - 3 } & Crédito consignado & \\
\end{tabular}

Fonte: Dados da pesquisa (2017). 
A ilustração do Quadro 4 permite, de maneira ilustrativa e resumida, identificar quais são os grupos com perfil mais arriscado, ou seja, que estão em maior vulnerabilidade financeira já que apresentam elevada atitude ao endividamento e baixo conhecimento financeiro. Nesse sentido, ao desenvolver ações com objetivo de melhorar a tomada de decisão financeira dos servidores públicos, a UFSC deve priorizar a capacitação de indivíduos com esse perfil.

Por fim, analisou-se a influência das variáveis de perfil e traços de personalidade na atitude ao endividamento e conhecimento financeiros, por meio de duas regressões múltiplas. Ressalta-se que antes de estimar os modelos de regressão propriamente ditos, alguns pressupostos do modelo foram analisados, tais como: multicolinearidade, homocedasticidade e autocorrelação. Quanto a multicolinearidade o índice VIF ficou igual a 1 indicando ausência de multicolinearidade. Verificando a homocedasticidade percebeu-se que os resíduos são homogêneos, confirmando a hipótese nula e atendendo ao pressuposto. Por fim, exibiu-se que a autocorrelação não está presente no modelo, pois o teste de Durbin Watson (DW) confirma que os erros na regressão são independentes, apresentando valores próximos a 20 que é considerado adequado por Hair et al. (2010). Após a conclusão dos testes de diagnóstico pode-se afirmar que os modelos de regressão estão adequados, assim, todos os resultados das regressões podem ser visualizados nas Tabelas 6 e 7.

Tabela 6 Resultados da regressão linear múltipla dos coeficientes padronizados e dos testes de significância do fator atitude ao endividamento em relação aos fatores e variáveis independentes que apresentaram significância estatística*

\begin{tabular}{l|c|c|c|c|c}
\multirow{2}{*}{ Modelo } & \multicolumn{2}{|c|}{ Coeficientes não-padronizados } & $\begin{array}{c}\text { Coeficientes } \\
\text { padronizados }\end{array}$ & \multirow{2}{*}{ Teste t } & Sig. \\
\cline { 2 - 5 } & B & Erro Padrão & Beta & 7,643 & 0,000 \\
\hline (Constante) & 2,333 & 0,305 & & 2,497 & 0,013 \\
\hline Extroversão & 0,065 & 0,026 & 0,115 & $-2,897$ & 0,004 \\
\hline Conscienciosidade & $-0,084$ & 0,029 & $-0,136$ & $-3,264$ & 0,001 \\
\hline Crédito Consignado & $-0,137$ & 0,042 & $-0,150$ & \multirow{2}{*}{0} \\
\hline
\end{tabular}

Fonte: Dados da pesquisa (2016).

* Foram suprimidas da tabela as variáveis que não mostraram-se significativas para o modelo: Conhecimento Financeiro, Simpatia, Neuroticismo, Abertura à experiência, Idade, Tempo de Serviço, Sexo, Estado Civil, Dependente, Nível de Escolaridade, Cargo, Moradia, Renda e Gastos.

O resultado apresenta um $\mathrm{R}^{2}$ ajustado de 0,058 , ou seja, as variáveis independentes explicam cerca de 5,8\% da variável dependente (atitude ao endividamento). $\mathrm{O}$ teste $\mathrm{F}$ atingiu um valor de 2,768 com significância de 0,000 , demonstrando que o modelo é significativo como um todo. Destaca-se ainda, que das 17 variáveis analisadas apenas três demonstraram influenciar a atitude ao endividamento, sendo elas: extroversão, conscienciosidade e crédito consignado.

Em relação ao traço da personalidade extroversão, identifica-se que este exerce influência positiva na atitude ao endividamento. De forma que quanto mais extrovertido é o servidor, maior atitude ao endividamento ele possui. Servidores com características de alta extroversão como assertivo, sociável, otimista e comunicativo, tendem a se endividar mais do que os servidores com características de baixa extroversão. Vale destacar que Brown e Taylor (2011) analisaram a influência dos traços de personalidade no endividamento, tendo como resultado que o traço de personalidade extroversão influencia a quantidade de dívidas.

A conscienciosidade exerce influência negativa sobre a atitude ao endividamento, de forma que servidores com alta conscienciosidade apresentam características como confiável, organizado, cauteloso e disciplinado, o que faz com que tenham menor propensão ao endividamento. Já os servidores com baixa conscienciosidade são espontâneos, divertidos, desorganizados e amorosos, o que os leva a ter uma atitude mais favorável ao endividamento. 
Outra variável que exerce influência sobre a atitude ao endividamento é crédito consignado. A influência é negativa, ou seja, a relação é inversamente proporcional, apontando que servidores que afirmaram não fazer uso de crédito consignado tem menor propensão ao endividamento. Ressalta-se que na questão sobre crédito consignado a alternativa 1 corresponde àquelas pessoas que fazem uso e 2 aquelas que não fazem uso dessa ferramenta, sendo este $o$ motivo que a relação é inversa, cujas respostas 2 no uso do crédito consignado resultarão em menores médias de atitude ao endividamento. Esse resultado está alinhado ao aumento considerável das ofertas de crédito nos últimos anos. Claudino, Nunes e Silva (2009) assim como Lira (2014) fizeram estudos com servidores públicos de outras universidades federais e observaram que a oferta excessiva de crédito aliada às facilidades no acesso são os dois principais ingredientes para o endividamento. A Tabela 7 apresenta os resultados da regressão que tem o conhecimento financeiro como fator dependente.

Tabela 7 Resultados da regressão linear múltipla dos coeficientes padronizados e dos testes de significância do fator conhecimento financeiro em relação aos fatores e variáveis independentes que apresentaram significância estatística*

\begin{tabular}{l|c|c|c|c|c}
\multirow{2}{*}{ Modelo } & \multicolumn{2}{|c|}{ Coeficientes não-padronizados } & $\begin{array}{c}\text { Coeficientes } \\
\text { padronizados }\end{array}$ & S \\
\cline { 2 - 5 } & B & Erro Padrão & Beta & Sig. \\
\hline (Constante) & 4,608 & 0,688 & & 6,697 & 0,000 \\
\hline Extroversão & $-0,117$ & 0,058 & $-0,092$ & $-2,013$ & 0,045 \\
\hline Sexo & $-0,370$ & 0,112 & $-0,155$ & $-3,302$ & 0,001 \\
\hline Idade & $-0,192$ & 0,075 & $-0,180$ & $-2,564$ & 0,011 \\
\hline Renda & 0,196 & 0,080 & 0,198 & 2,446 & 0,015 \\
\hline Crédito Consignado & 0,196 & 0,094 & 0,095 & 2,086 & 0,038 \\
\hline
\end{tabular}

Fonte: Dados da pesquisa (2016).

* Foram suprimidas da tabela as variáveis que não se mostraram significativas para o modelo: Afabilidade, Conscienciosidade, Neuroticismo, Abertura à experiência, Estado Civil, Nível de Escolaridade, Dependente, Cargo, Moradia, Gastos, Tempo de Serviço e Atitude ao Endividamento.

O resultado apresenta um $\mathrm{R}^{2}$ ajustado de 0,074 indicando que as variáveis independentes explicam cerca de 7,4\% da variável dependente (conhecimento financeiro). O teste $\mathrm{F}$ atingiu um valor de 3,288 com significância 0,000 , demonstrando que o modelo é significativo como um todo. Destaca-se ainda que das 17 variáveis exploradas, cinco mostraram-se impactantes no conhecimento financeiro, são elas: extroversão, sexo, idade, renda e crédito consignado.

$\mathrm{O}$ traço de personalidade extroversão exerce influência negativa sobre o fator conhecimento financeiro. Sendo assim, servidores com características de alta extroversão como assertivo, sociável, otimista e comunicativo, tendem a não ter conhecimento financeiro. Servidores que apresentem características de baixa extroversão como alguém independente, sozinho, reservado e difícil de entender, tem maior propensão a ter conhecimento financeiro, talvez por serem mais introspectivos e dedicarem-se mais aos estudos.

O "sexo" também é uma variável relacionada ao conhecimento financeiro. Tanto Potrich et al. (2014) como Lusardi e Mitchell (2011) também chegarem nesta conclusão, enfatizando que mulheres apresentam menos conhecimento financeiro do que homens, pois os homens geralmente são mais incentivados a lidar com aspectos financeiros.

Quanto a variável “idade” verifica-se uma influência negativa do fator conhecimento financeiro. Assim, quanto maior a idade, menor o conhecimento financeiro, ratificando os achados de Claudino, Nunes e Silva (2009), os quais demonstram que pessoas mais jovens apresentam mais conhecimento financeiro do que os mais velhos. O que é justificável considerando 
que há algumas décadas o acesso à educação financeira era mais limitado do que atualmente.

Quanto à variável "Renda" a influência é positiva indica que servidores com maiores níveis de renda apresentam maior conhecimento financeiro. Esse resultado já era esperado, já que, na maioria dos casos, o nível de escolaridade dos servidores públicos impacta diretamente seu nível salarial. Nessa mesma perspectiva, Claudino, Nunes e Silva (2009) afirmam que a posse de maior renda por alguns servidores, provavelmente se justifica ao fato destes terem maior conhecimento financeiro e o utilizarem no seu dia-a-dia.

Observa-se também que a variável "crédito consignado" exerce uma influência positiva em relação ao conhecimento financeiro, ou seja, servidores que afirmaram não fazer uso do crédito consignado tem maior conhecimento financeiro. De acordo com Lira (2014) um grande número de servidores faz empréstimos que comprometem expressiva parte da renda sem refletir sobre a real necessidade, bem como, sem refletir sobre questões como os juros que estão pagos, se existem outras taxas embutidas, e principalmente, as consequências desse empréstimo no orçamento em longo prazo. De forma que, aqueles que possuem conhecimento financeiro para resolver e refletir sobre essas questões, o utilizam adequadamente evitando os problemas com o crédito.

Com base nos resultados das regressões foi possível construir, no Quadro 4, uma síntese das variáveis significativas para esta pesquisa evidenciando as influências das variáveis nos fatores estudados.

Quadro 4 Síntese regressão das variáveis que foram significativas.

\begin{tabular}{l|l|l}
\multirow{2}{*}{ Fator } & Variáveis Significativas & Influência encontrada \\
\hline \multirow{2}{*}{$\begin{array}{l}\text { Atitude ao } \\
\text { Endividamento }\end{array}$} & Extroversão & Alta Extroversão = Maior Atitude ao Endividamento \\
\cline { 2 - 3 } & Conscientização & Baixa Conscientização = Maior Atitude ao Endividamento \\
\cline { 2 - 3 } & Crédito consignado & Quem faz ou já fez uso do crédito consignado = Maior Atitude ao Endividamento \\
\hline \multirow{2}{*}{\begin{tabular}{l} 
Financeiro \\
\cline { 2 - 3 }
\end{tabular}} & Extroversão & Alta Extroversão = Menor Conhecimento Financeiro \\
\cline { 2 - 3 } & Sexo & Mulheres $=$ Menor Conhecimento Financeiro \\
\cline { 2 - 3 } & Idade & Menor renda $=$ Menor Conhecimento Financeiro \\
\cline { 2 - 3 } & Renda & Quem faz ou já fez uso do crédito consignado = Menor Conhecimento Financeiro \\
\cline { 2 - 3 } & Crédito consignado & Mincento Financeiro \\
\hline
\end{tabular}

Fonte: Dados da pesquisa (2017).

\section{CONSIDERAÇÕES FINAIS}

Atualmente, menos da metade dos adultos no mundo possuem conhecimentos financeiros e, além disso, grande parte das famílias brasileiras está endividada, o que demonstra a necessidade de aprofundar os estudos nesses temas considerando realidades mais próximas ao cotidiano. Partindo desse contexto, o objetivo do presente estudo foi identificar quais aspectos influenciam a atitude ao endividamento e o conhecimento financeiro de servidores da Universidade Federal de Santa Catarina considerando variáveis de perfil e traços de personalidade.
Os resultados obtidos evidenciaram que os servidores possuem principalmente os traços de personalidade "conscientização" e "abertura à experiência", que possuem conhecimento em conceitos básicos de finanças e que evidenciam pouca atitude favorável ao endividamento. Também foi possível identificar que os servidores com maior risco de apresentarem atitude favorável ao endividamento são os que possuem imóvel financiado, gastam mais do que ganham e fazem ou já fizeram uso de crédito consignado. Observou-se ainda que os servidores mais propensos a apresentarem baixo conhecimento financeiro são do sexo feminino, com mais idade, menos tempo de 
serviço, que gastam mais do que ganham e fazem ou já fizeram uso de crédito consignado. Tais achados evidenciam um perfil específico de pessoas que estão mais vulneráveis a problemas financeiros, contribuindo assim para a identificação dos grupos que devem ser priorizados em programas de educação financeira que podem vir a ser desenvolvidos na instituição.

Os resultados das regressões revelaram que os traços de personalidade "extroversão" e "conscienciosidade", bem como a variável "crédito consignado" tem impacto na atitude financeira, sendo que servidores com alta extroversão, baixa conscientização e que já fizeram ou fazem uso do crédito consignado são os mais propensos a ter atitude ao endividamento. Da mesma forma, percebeu-se que deve haver uma maior preocupação com colaboradores de alta extroversão, mulheres, com mais idade, menor renda e que fazem ou já fizeram uso do crédito consignado, pois estes são os servidores com maior tendência a menores níveis de educação financeira. Esses resultados são de grande valia, já que apontam os fatores determinantes da atitude ao endividamento e do conhecimento financeiro de servidores da UFSC.

Destaca-se ainda que uma das contribuições deste estudo é a incorporação dos traços de personalidade como determinantes da atitude ao endividamento e educação financeira de servidores, aspecto que ainda não havia sido explorado em estudos anteriores. Além disso, mesmo que boa parte dos servidores tenha apresentado elevado conhecimento financeiro, ainda há necessidade de capacitações na área de finanças, que sejam capazes de fornecer conhecimentos de conceitos básicos de finanças e permitir que os servidores tenham maior qualidade eu suas decisões financeiras. Esses cursos devem ser dedicados principalmente aos servidores que estiverem dentro do perfil de risco evidenciados pelos testes estatísticos, ou seja, aqueles mais propensos a apresentar maior atitude ao endividamento e menor conhecimento financeiro, bem como deve destinar-se a atender as necessidades apresentadas e preencher as áreas com mais defasagem como o conceito de diversificação.

Ressalta-se ainda, que a importância deste trabalho se dá pela possibilidade de estender esses resultados para gerar contribuições em outras universidades. Dessa forma, a partir dos resultados desta pesquisa é possível desenvolver ações de capacitação direcionadas aos servidores de outras instituições federais de ensino superior, e não só exclusivamente aos servidores da UFSC, já que, durante as análises foi possível verificar que o perfil dos servidores de uma instituição federal de ensino superior pode ser bastante semelhante à outra, como no caso aqui apresentado da UFSC e da UFSM.

Como limitação do estudo ressalta-se à possibilidade de que os servidores que não responderam à pesquisa sejam os que tenham maior atitude ao endividamento e revelem mais falta de conhecimento financeiro. Ou justamente o oposto, apenas os servidores que estavam com problemas financeiros poderiam se interessar por uma pesquisa dessas, a fim de encontrar uma solução. Outro fator limitante é que servidores que não possuíam e-mail não foram atingidos pela pesquisa. Finalmente, como sugestão para trabalhos futuros, recomenda-se estudos utilizando outras variáveis que possam interferir no desempenho financeiro dos servidores, como vieses e heurísticas. Ou ainda, uma pesquisa para avaliar o letramento financeiro, mensurando atitudes, conhecimentos e comportamentos financeiros dos servidores.

\section{REFERÊNCIAS}

ATKINSON, Adele; MESSY, Flore-Anne. Measuring financial literacy: results of the OECD infe pilot study. Papers on Finance, Insurance and Private Pensions - OECD Publishing, v. 15, p. 01-73, 2012.

BAEK, Eunyoung; HONG, Gong-Soog. Effects of family life-cycle stages on consumer debts. Journal of Family and Economic Issues, v. 25, n. 3, p. 359385, 2004.

BANCO CENTRAL DO BRASIL - BACEN. Caderno de Educação Financeira - Gestão de Finanças Pessoais (Conteúdo Básico). Brasília: BCB, 2013. 72 p. Disponível em: <http://www.bcb.gov.br/pre/pef/ port/caderno_cidadania_financeira.pdf $>$. Acesso em: 19 jun. 2016. 
BERG, Carla ; SANEM, Julia; LUST, Katherine; AHLUWALIA, Jasjit; KIRC, Matthias; LAWRENCE, An; Health-related characteristics and incurring credit card debt as problem behaviors among college students. The Internet Journal of Mental Health, 2010.

BORGHANS, Lex; DUCKWORTH, Angela Lee; HECKMAN, James; WEEL, Bas Ter. The economics and psychology of personality traits. Journal of human Resources, v. 43, n. 4, p. 972-1059, 2008.

BORTOLI, Daiane de. Traços da personalidade, avaliação do perfil do investidor e teoria do prospecto: um estudo em finanças comportamentais para identificar o comportamento dos indivíduos em decisões mediante risco. 2016. 129 f. Dissertação (Mestrado) - Programa de Pós-graduação em Economia, Centro Socioeconômico, Universidade Federal de Santa Catarina, Florianópolis, 2016. Disponível em: <https://repositorio.ufsc.br/xmlui/ bitstream/handle/123456789/167803/340643.pdf?sequence $=1$ \&isAllowed $=y>$. Acesso em: 09 jan. 2017 .

BORTOLI, Daiane de; COSTA JR, Newton Carneiro Affonso da; GOULART, Marco Antônio De Oliveira Vieira. Teoria do prospecto, traços da personalidade, teste de reflexão cognitiva e avaliação do perfil do investidor: um estudo em finanças comportamentais. 2015.

BROWN, Sarah; TAYLOR, Karl. Household finances and the $\bigotimes$ Big Five $\bigotimes$ personality traits. Discussion Paper Series, Institute for the Study of Labor (IZA). n. 6191. 2011.

CAMPARA, Jéssica Pulino; VIEIRA, Kelmara Mendes; CERETTA, Paulo Sergio. Entendendo a atitude ao endividamento: fatores comportamentais e variáveis socioeconômicas o determinam?[doi: 10.21529/RECADM. 2016002]. Revista Eletrônica de Ciência Administrativa-RECADM, v. 15, n. 1, p. 5-24, 2016.
CLAUDINO, Lucas Paravizo; NUNES, Murilo Barbosa; SILVA, Fernanda Cristina da. Finanças Pessoais: um estudo de caso com servidores públicos. XII SEMEAD - Seminários em Administração, São Paulo, ago. 2009.

CONFEDERAÇÃO NACIONAL DO COMÉRCIO DE BENS, SERVIÇOS E TURISMO - CNC. Pesquisa de Endividamento e Inadimplência do Consumidor: maio de 2017. 2017. Disponível em: < http://cnc.org. $\mathrm{br} /$ central-do-conhecimento/pesquisas/economia/ pesquisa-nacional-de-endividamento-e-inadimplencia-do--30?utm_source=akna\&utm_medium $=\mathrm{e}$ mail\&utm_campaign=Release+Peic +-+ maio+2017>. Acesso em: 02 maio. 2017.

DAVIES, Emma; LEA, Stephen EG. Student attitudes to student debt. Journal of economic psychology, v. 16, n. 4, p. 663-679, 1995.

DELAVANDE, Adeline; ROHWEDDER, Susann.; WILLIS, Robert. Retirement Planning and the Role of Financial Literacy and Cognition. In: Michigan Retirement Research Center, Working Paper 2008190. 2008.

DISNEY, Richard; GATHERGOOD, John. Financial Literacy ad Indebtedness: New Evidence for UK Consumers. 2011.

EYSENCK, Hans Jürgen; EYSENCK, Michael William.Personalidad y diferencias individuales. Madrid: Pirámides, 1987.

\section{FECOMERCIOSC. Pesquisa de Endividamento} e Inadimplência do Consumidor. Núcleo de Estudos Estratégicos Fecomércio-SC, dez. 2016. 2016. Disponível em: <http://www.fecomercio-sc.com.br/ fmanager/fecomercio/pesquisas/arquivo538_1.pdf>. Acesso em: 24 jan. 2017.

FLORES, Silva Amélia Mendonça. Modelagem de equações estruturais aplicada à propensão ao endividamento: uma análise de fatores comportamentais. 2012. 192 f. Dissertação (Mestrado em Administração) - Universidade Federal de Santa Maria, 2012. 
FLORES, Silvia Amélia Mendonça; VIEIRA, Kelmara Mendes, CORONEL, Daniel Arruda. Influência de fatores comportamentais na propensão ao endividamento. Revista Adm. FACES, v. 12, n. 2, p. 13-35, abr./jun., 2013.

GOSLING, Samuel; RENTFROW, Peter; SWANN JR., William. A very brief measure of the Big-Five personality domains. Journal of Research in Personality, 37, 504-528, 2003.

HAIR, Joseph; BLACK, William; BABIN, Barry; ANDERSON, Rolph. Multivariate Data Analyses. 7 ed. New Jersey: Pearson, 2010.

HOFMANN, Ruth Margareth; MORO Maria Lucia Faria. Educação matemática e educação financeira: perspectivas para a ENEF. Rev. Zetetiké - FE/ Unicamp - v. 20, n. 38 - jul/dez, 2012.

HUANG, Jiekun; KISGEN, Darren J. Gender and corporate finance: Are male executives overconfident relative to female executives?. Journal of Financial Economics, v. 108, n. 3, p. 822-839, 2013.

KATONA, George. Psychological economics. New York: Elsevier, 1975.

KEESE, Matthias. Who Feels Constrained by High Debt Burdens? Subjective vs. Objective Measures of Household Indebtedness. RUHR Economic Papers, Germany, 2010.

KEESE, Matthias. Who feels constrained by high debt burdens? Subjective vs. objective measures of household debt. Journal of Economic Psychology, v. 33, n. 1, p. 125-141, 2012.

KLAPPER, Leora; LUSARDI, Annamaria; OUDHEUSDEN, Peter Van. Financial Literacy Around the World. Insights From The Standard \& Poor's Ratings Services Global Financial Literacy Survey, 2015.
LEA, Stephen Edmund Gillam; WEBLEY, Paul; LEVINE, Mark. The economic psychology of consumer debt. Journal of Economic Psychology, 14, p. 85-119, 1993.

LIRA, Caetano Correia. Crédito consignado: cenários no Brasil e diagnóstico na UFPE (2010 a 2012). Dissertação de Mestrado em Gestão Pública. 2014.

LIVINGSTONE, Sonia; LUNT Peter. Predicting personal debt and debt repayment: Psychological, social and economic determinants. Journal of Economic Psychology 13, 111-134, 1992.

LUCKE, Viviane Aparecida Caneppele; FILIPIN, Roselaine; VIEIRA, Euselia Paveglio; BRIZOLLA, Maria Margarete Baccin. Comportamento financeiro pessoal: um comparativo entre jovens e adultos de uma cidade da região noroeste do estado do RS. Anais dos Seminários em Administração, São Paulo, SP, Brasil, v. 17, 2014.

LUSARDI, Annamaria. The Importance of Financial Literacy and the Effectiveness of Financial Education. Financial Education and Investor Behavior Conference - Rio, dez, 2015. Disponível em: $<$ http://pensologoinvisto.cvm.gov.br/wp-content/ uploads/2015/12/AnnamariaLusardi-presentationIEC2015.pdf>. Acesso em: 15 mai. 2016.

LUSARDI, Annamaria; MITCHELL, Olivia S. Financial literacy and retirement planning in the United States. Journal of Pension Economics and Finance, Cambridge University Press, v. 10, n. 04, p. 509-525, 2011.

LUSARDI, Annamaria; WALLACE, Dorothy. Financial literacy and quantitative reasoning in the high school and college classroom. Numeracy, v. 6, n. 2, 2013.

MILANEZ, Daniel Yabe. Finanças comportamentais no Brasil. Tese (Doutorado em Economia) Universidade de São Paulo, 2003. 
MOTTOLA, Gary. In our best interest: Women, financial literacy, and credit card behavior. Numeracy, v. 6, n. 2, art. 4, 2013.

MOURA, Ana Grisanti de. Impacto dos Diferentes Níveis de Materialismo na Atitude ao Endividamento e no Nível de Dívida para Financiamento do Consumo nas Famílias de Baixa Renda do Município de São Paulo. Dissertação (Mestrado em Administração de Empresas) - Escola de Administração de Empresas de São Paulo da Fundação Getulio Vargas, São Paulo, 2005.

NOGUEIRA, Roberto Carneiro Gurgel. Finanças comportamentais: diferenças na tolerância de risco entre cônjuges -

replicando uma pesquisa e propondo alternativas complementares. 2009. 80 p. Dissertação de Mestrado - Departamento de Administração, Pontifícia Universidade Católica do Rio de Janeiro, 2009.

OBSERVATÓRIO DE ENDIVIDAMENTO DOS CONSUMIDORES. Endividamento e sobreendividamento das famílias: Conceitos e estatísticas para sua avaliação. Centro de Estudos Sociais da Faculdade de Economia da Universidade de Coimbra, Fev, 2002.

OLIVATO, Herica; SOUZA, Patricia Keli. Botari. Endividamento: um estudo preliminar dos fatores contribuintes. Anais do Simpósio de Educação e do Encontro Científica de Educação da Unisalesiano, Lins/São Paulo, 2007.

ORGANIZAÇÃO PARA A COOPERAÇÃO E DESENVOLVIMENTO ECONÔMICO - OCDE. Recommendation on Principles and Good Practices for Financial Education and Awareness. Recommendation of the Council. Jul, 2005.

PONCHIO, Mateus Canniatti. The Influence of Materialism on Consumption Indebtedness in the Context of Low Income Consumers From the City of Sao Paulo. [Tese de Doutorado]. Escola de Administração de Empresas de São Paulo da Fundação Getúlio Vargas. São Paulo, p. 175. 2006.
POTRICH, Ani Caroline Grigion. Alfabetização Financeira: Integrando conhecimento, Atitude e comportamento financeiros. 2014. 178 f. Dissertação (Mestrado) - Curso de Curso de Mestrado do Programa de Pós-Graduação em Administração, Universidade Federal de Santa Maria.

POTRICH, Ani Caroline Grigion; VIEIRA, Kelmara Mendes; CAMPARA, Jéssica Pulino; FRAGA, Luana dos Santos; SANTOS, Luis Felipe de Oliveira. Educação Financeira dos Gaúchos: Proposição de uma Medida e Relação com as Variáveis Socioeconômicas e Demográficas. Sociedade, Contabilidade e Gestão, v. 9, n. 3, 2014.

RAMMSTEDT, Beatrice; JOHN, Oliver. Measuring personality in one minute or less: A 10-item short version of the Big Five Inventory in English and German. Journal of research in Personality, v. 41, n. 1, p. 203-212, 2007.

SAVOIA, José Roberto Ferreira; SAITO, André Taue; SANTANA, Flavia de Angelis. Paradigmas da educação financeira no Brasil. Revista de Administração pública, v. 41, n. 6, p. 1121-1141, 2007.

SILVA, Luiz Fernando; VIEIRA, Valter Afonso; DA SILVA FAIA, Valter. Fatores determinantes do endividamento e da inadimplência associados à propensão de falência da pessoa física. AnáliseRevista de Administração da PUCRS, v. 23, n. 3, p. 207-221, 2015.

TOKUNAGA, Howard. The use and abuse of consumer credit: Application of psychological theory and research. Journal of Economic Psychology 14, 285-316, 1993

VERDINELLI, Miguel Angel; LIZOTE, Suzete Antonieta; OLIVARES, Adriana. Conhecimentos financeiros no âmbito universitário: uma análise com estudantes do Brasil e Venezuela. Colóquio Internacional de Gestão Universitária. 2014. 
ZERRENNER, Sabrina Arruda. Estudo Sobre as razões para a população de baixa renda. Dissertação (Mestre em Ciências Administrativas) - Universidade de São Paulo, São Paulo, 2007.

YOSHINAGA, Claudia Emiko; OLIVEIRA, Raquel. Freitas. de; SILVEIRA, Alexandre Di Miceli; BARROS, Lucas Ayres Barros. .Finanças comportamentais: uma introdução. Revista de Gestão USP, v. 15 , p. $25-35$, jul-set, 2008. 